\title{
Self Esteem, Anxiety, Depression and Stress among Physically Disabled People
}

\author{
Shahnawaz Mushtaq ${ }^{1 *}$, Dr Deoshree Akhouri $^{2}$
}

\section{ABSTRACT}

Background: The aim of the present study is to investigate the self esteem, anxiety, stress and level of depression among the individuals who are differently able. The study investigated the psychological stressors, mental health and self image of the physically challenged people. Any physical disability leads to feelings of inadequacy which results in the feelings of depression, anxiety and low levels of tolerance. Material And Method: 50 physically challenged and 50 normal women and men were taken for the study. Result And Discussion: It was found that physically disabled people have low level of self esteem and high level of depression, stress and anxiety in comparison to normal population.

Keywords: Self Esteem, Depression, Physically Challenged, Anxiety.

The present study focuses on the distorted self esteem and the high level of depression, stress and anxiety among the physically disabled. According to International Classification of Functional Disability (ICF), physical disability is a state with remarkable defect, limitation or inability of certain organs or processes of the body, which create hurdle in carrying out normal physical movements and thus affect normal functioning in different areas of life (WHO, 2001 as cited in Chang \& Johnson, 2008). Individual having any kind of disability has faced the problem in interacting with the society at one time or the other. Disability results in the limitation of performance in one or more activities that are essential for the daily living. This means the individual is incapable of some degree of independence (Reynell, 1970). Disability limits the individual's opportunity and creates frustration. It also creates a sense of prejudice among disabled and able bodied. The degree of disability of a person is measured on the basis of the demands of the surroundings in which he or she is living and his or her inability to meet those demands. From a vocational and educational perspective, there are three categories of disabled

\footnotetext{
${ }^{1}$ Ph.D Scholar, Jawaharlal Nehru Medical College, Aligarh Muslim University, Aligarh, India

${ }^{2}$ Assistant Professor Department of Psychiatry, Jawaharlal Nehru Medical College, Aligarh Muslim University, Aligarh, India

*Responding Author

(C) 2016, S Mushtaq, D Akhouri; licensee IJIP. This is an Open Access Research distributed under the terms of the Creative Commons Attribution License (http://creativecommons.org/licenses/by/2.0), which permits unrestricted use, distribution, and reproduction in any Medium, provided the original work is properly cited.
} 


\section{Self Esteem, Anxiety, Depression and Stress among Physically Disabled People}

namely, those who are capable of being full educated and productive and are able to compete with the able-bodied; those who are partially productive because they cannot acquire speech and skills required to compete with the able-bodied; and those with serious disability who remain totally unproductive. However, the disabled individual can raise himself/herself from a lower to higher level as a result of social conditioning, technical change or fashion. The disabled individual may likewise regress to a lower level due to personality maladjustment (Jennings, 1988). Disabled individuals have problem of adjustment in a society that labels anyone that does not fit the description of the normal individuals. This led Cusforth (1951) to conclude that society's negative reaction to the disabled was entirely responsible for their emotional problem.

Self-esteem involves an individual evaluating his/her image progressively or regressively (Roessler, 1978). Self-esteem has a prominent role in the mental health and personality balance. This evaluation is believed to be relevant to the individual's optional adjustment and functioning. Self-esteem with reference to disability can be defined as a disabled person evaluating his/her capacity to perform in the society. . Low self-esteem unsettles human's balance and vitality and negatively influences the efficacy, efficiency learning and creativity of physically disabled humans. It is characterized by the feeling of inadequate, guilt, shyness, social inhibition, independency, helplessness, masked hospitality, withdrawal, complainer, tendency to downgrade others, reduced ability, accepting unfavourable assessment as accurate, vulnerability and interpersonal problem (Robson, 1988). One of the most disastrous outcomes of defected inefficient self-esteem is the slowed personal function and person's reduced efficiency. This defected self esteem deprive person of using complete mental and intellectual power. However, it was stereotyped that male are prone to more self-esteem than female. This is because male tends to base their image on individualism while female base theirs on care (Cohen, 1977). The survey of Stikland and Angimary (2004) on self-esteem and body image of physically disabled persons shows that physical health has a positive significant relationship with self-esteem and assessment of self. Level of self-esteem will decrease in the existence of physical disability. Depression is also a very serious problem among physically disabled. A person having depression feels very low which hinders his activities of daily living. A study was conducted by Hussain, N. Et al in 2014 to assess the level of depression among physically handicapped. Present study has found that physical disability is a risk factor for the development of depression. The study indicates that there are symptoms of depression in people with physical disability according the disability symptoms may be mild, moderate or severe. Disabled persons were at substantially elevated risk for depressive symptoms and major depressive disorder. Results shows that out of 35 individuals $2.86 \%$ were of mild mood disturbance, $42086 \%$ were moderately depressed, $37.14 \%$ severely depressed and $14.29 \%$ were in extreme depression. Results clearly demonstrate that physical disability can lead to depression.

Physical disability either congenital or acquired may lead to feelings of inadequacy (Chang \& Johnson, 2008). Marschark (1993) suggested a strong relationship between physical and mental 
functioning in humans because any type of physical or sensory deficiency disturbs one's overall psychological functioning by creating an obstruction in normal flow of such processes, leading to an experience of the world, which is distinct in context. People who experience physical impediment are more likely to have low frustration tolerance (McDermoort \& Akina, 1972; Dell Orto \& Power, 2007). Many individuals with physical disability experience anxiety (Boswell \& Wingrove, 1974) and also experience depression due to loss and as well as due to the changed behaviours of people around them (Krueger, 1984). Disabilities are often associated with vulnerable self-esteem (Nosek et al., 2003; Gill, 1996; Cornwell \& Schmitt, 1990). It has a negative effect on those who were ambitious and could have achieved their life goals easily in the absence of their present disability (Goodwill \& Chamberlain, 1988). Narimani and Mousazadeh (2010) also found a significant difference in the mean scores of handicapped and normal students on self-esteem. Lasker et al. (2010) noted similar severe psychosocial problems in children with disability in comparison to the healthy ones. Puranen, Seuri, Simoli and Elo (1999) found that participants displayed symptoms of anxiety and depression more commonly than general population.

Above given research evidences show that there is low level of self esteem and high level of depression, stress and anxiety among the physically disabled people. Though there is a need of much more research in this phenomenon to explore it in a better way.

\section{METHODOLOGY}

\section{Objectives:}

1. To find out the level of self esteem among physically disabled people.

2. To find out the level of depression among physically disabled people.

3. To find out the level of stress among physically disabled people.

4. To find out the level of anxiety among physically disabled people.

\section{Participants:}

The data was collected randomly on 50 physically handicapped females and males and 50 normal people were taken as a sample for the study from Jawaharlal Nehru Medical College, Aligarh Muslim University, Aligarh.

\section{Tools:}

- DEPRESSION, ANXIETY, STRESS SCALE (DASS): The DASS developed by Lovibond and Lovibond (1995) is a 21 item self report questionnaire designed to measure the severity of a range of symptoms common to both Depression and Anxiety. In completing the DASS, the individual is required to indicate the presence of a symptom over the previous week. Each item is scored from 0 (did not apply to me at all over the last week) to 3 (applied to me very much or most of the time over the past week). The essential function of the DASS is to assess the severity of the core symptoms of 
Depression, Anxiety and Stress. Accordingly, the DASS allows not only a way to measure the severity of a patient's symptoms but a means by which a patient's response to treatment can also be measured. Both English and non-English versions of DASS have high internal consistency (Cronbach's alpha scores of $>0.7$ ).

- ROSENBERG SELF ESTEEM SCALE: This scale was developed by Rosenberg in the year 1965.The scale is a ten item Likert scale with items answered on a four point scale - from strongly agree to strongly disagree. Internal consistency for the Rosenberg self esteem scale range from 0.77 to 0.88 . Test-retest reliability for the RSE range from 0.82 to 0.85 .

\section{Procedure:}

The data was collected on subjects individually by administering DASS and Rosenberg Self Esteem scale. Prior to data collection researcher had to establish a rapport with the subject. The purpose of the research was explained to the subject to develop the subject's keen interest to cooperate the task and after the subject's readiness to support the purpose, they were asked to fill the questionnaires. After the completion of the questionnaires subject was told that his or her responses would be kept confidential and should be used for research purpose only.

\section{RESULT AND DISCUSSION}

TABLE-1, Showing the difference in the level of depression between physically challenged and normal population

\begin{tabular}{|l|l|l|l|l|}
\hline Groups & N & M & S.D & t \\
\hline Physically disabled & 50 & 18.5 & 3.63 & 18.431 \\
\hline Normal population & 50 & 7.2 & 2.40 & 18.431 \\
\hline
\end{tabular}

TABLE-2, Showing the difference in the level of anxiety between physically challenged and normal population

\begin{tabular}{|l|l|l|l|l|}
\hline Groups & N & M & S.D & t \\
\hline Physically disabled & 50 & 15.4 & 2.77 & 22.631 \\
\hline Normal population & 50 & 4.4 & 2.00 & 22.631 \\
\hline
\end{tabular}

TABLE-3, Showing the difference in the level of stress between physically challenged and normal population

\begin{tabular}{|l|l|l|l|l|}
\hline Groups & N & M & S.D & t \\
\hline Physically disabled & 50 & 26.8 & 3.90 & 24.649 \\
\hline Normal population & 50 & 8.3 & 3.56 & 24.649 \\
\hline
\end{tabular}


Self Esteem, Anxiety, Depression and Stress among Physically Disabled People

TABLE-4, Showing the difference in the level of self esteem between physically challenged and normal population

\begin{tabular}{|l|l|l|l|l|}
\hline Groups & N & M & S.D & t \\
\hline Physically disabled & 50 & 10.2 & 1.60 & -21.545 \\
\hline Normal population & 50 & 17.7 & 1.84 & -21.545 \\
\hline
\end{tabular}

TABLE-5, Showing the correlation between high level of depression, stress and anxiety with low level of self esteem

\begin{tabular}{|l|l|l|l|l|l|}
\hline \multicolumn{2}{|c|}{} & Depression & Anxiety & Stress & Self esteem \\
\hline \multirow{4}{*}{ Depression } & Pearson Correlation & 1 & $.856^{* *}$ & $.794^{* *}$ & $-.797^{* *}$ \\
\cline { 2 - 6 } & Sig. (1-tailed) & & .000 & .000 & .000 \\
\cline { 2 - 6 } & $\mathrm{N}$ & 100 & 100 & 100 & 100 \\
\hline \multirow{4}{*}{ Anxiety } & Pearson Correlation & $.856^{* *}$ & 1 & $.863^{* *}$ & $-.829^{* *}$ \\
\cline { 2 - 6 } & Sig. (1-tailed) & .000 & & .000 & .000 \\
\cline { 2 - 6 } & $\mathrm{N}$ & 100 & 100 & 100 & 100 \\
\hline \multirow{3}{*}{ Stress } & Pearson Correlation & $.794^{* *}$ & $.863^{* *}$ & 1 & $-.806^{* *}$ \\
\cline { 2 - 6 } & Sig. (1-tailed) & .000 & .000 & & .000 \\
\cline { 2 - 6 } & $\mathrm{N}$ & 100 & 100 & 100 & 100 \\
\hline \multirow{3}{*}{ Self esteem } & Pearson Correlation & $-.797^{* *}$ & $-.829^{* *}$ & $-.806^{* *}$ & 1 \\
\cline { 2 - 6 } & Sig. (1-tailed) & .000 & .000 & .000 & \\
\cline { 2 - 6 } & $\mathrm{N}$ & 100 & 100 & 100 & 100 \\
\hline \multirow{2}{*}{$* *$ Correlation } & is significant at the 0.01 level (1-tailed). & & \\
\hline
\end{tabular}

\section{CONCLUSION}

Physical disability creates a sense of dependence this result in frustration, stress and anxiety it leads to the low level of self esteem. It can be clearly seen from the above given tables that there is a significant difference between the mean scores of physically challenged and normal population on the level of depression, anxiety, stress and self esteem. The mean score of depression of physically disabled is 18.5 which are much more than the score of normal population that is 7.2. Similarly the scores of physically disabled people on anxiety scale are 15.4 which are higher than the scores of normal people which are 4.4. The mean scores of stress obtained by physically challenged are 26.8 which are higher than the mean scores of normal population that is 8.3 on the same scale. These scores are clearly denoting the difference in the level of depression, anxiety and stress between the normal population and the physically handicapped. Physically challenged people are much higher on the levels of stress, anxiety and depression because of the helplessness, hopelessness, frustration, sense of dependence, loss and changed behaviour of people around them. They feel that their life could have been on some other track if they are not less fortunate. People who know that they cannot achieve their desired goals because of their disability feel much more depressed. They do not feel to be fit in the society of normal people. They sometimes or the other faced difficulty in interacting with the

(C) The International Journal of Indian Psychology, ISSN 2348-5396 (e)| ISSN: 2349-3429 (p) | 129 


\section{Self Esteem, Anxiety, Depression and Stress among Physically Disabled People}

society. Physically challenged people are also unable to support themselves in their daily living which results in a sense of dependence to some extent on others and it leads to frustration which is a cause of stress and anxiety. Physical unattractiveness is also an important factor leads to depression in physically disabled people. Also at the same time they have distorted self esteem which can be seen from the above given table. The scores of physically challenged on the self esteem are 10.2 which are much less than the scores of normal population which are 17.7. Low level of self esteem results from the feeling of inadequate, guilt, shyness, social inhibition, independency, helplessness, withdrawal, masked hospitality, etc. They feel themselves as less efficient than the able-bodied and lack self confidence. They are not able to trust others as well as themselves. They lose motivation, are not able to stand in front of the normal people. They stop believing in themselves. There is also a positive correlation between low level of self esteem and high level of depression, anxiety and stress as shown in table 5 . As the level of depression, stress and anxiety starts increasing, the self esteem of an individual starts declining. When a person starts thinking of himself as useless, he starts losing his self confidence as a result his motivational level and the belief on ones abilities declined, it fills the person with negativity and this negative self image will be the reason for low level of self esteem. But as they start living with their disability and accept the fact that they are not less fortunate than others and stop blaming themselves or others for their disability they are able to adapt with the situation effectively and as a result their self esteem starts enhancing and the level of depression, stress and anxiety starts declining. There is a need of change in the attitude of the society towards the disabled, as well as the physically challenged people also need to change their own attitude towards themselves. A quality of work has been done in this field but there is a need of much more research and a number of positive initiatives in order to solve the issue.

\section{Acknowledgments}

The author appreciates all those who participated in the study and helped to facilitate the research process.

\section{Conflict of Interests}

The author declared no conflict of interests.

\section{REFERENCES:}

Boswell, D., \& Wingrove, J. M. (1974). The handicapped person in the community: A reader and sourcebook. London: The Open University.

Chang, E. \& Johnson, A. (2008). Chronic illness and disability: Principles for nursing care. Australia: Elsevier.

Cohen, S. (1977) Noise and inattentiveness to social cues. Environment and Behaviour, 9(4), 559-572. 


\section{Self Esteem, Anxiety, Depression and Stress among Physically Disabled People}

Cornwell, C.J., \& Schmitt, S. (1990). Perceived self esteem, health status, and body image in women with Rheumatoid Arthritis or Systemic Lupus Erythematosus. Research in Nursing and Health, 13, 99- 107.

Cusforth, Z. (1951) Academic value of research participation by undergraduates. American Psychologist, 41, 317.

Dell Orto, A. E., \& Power, P. W. (Eds.). (2007). The psychological and social impact of illness and disability (5th ed.). New York: Springer Publishing Company.

Gill, C. J. (1996). Becoming visible: Personal health experiences of women with disabilities. In D.M., Kotoski, \& M.A., Turk, (Eds.), Women with physical disabilities: Achieving and maintaining health and well-being (pp.5-15). Baltimore: Brookes

Goodwill, C. J., \& Chamberlain, M. A., (1988). Rehabilitation of the physically disabled adult. New York, NY: Sheridan House.

Hussain, N., Sikander, M., \& Maqsud, M., (2014). Level of Depression in Physically Disabled. Journal of Riphah College of Rehabilitaion Sciences, 2(2), 12-15.

Jennings, J. (1988) Influence of television commercials on women's self confidence and independence judgment. Journal of Personality and Social Psychology, 38, 203-10.

Laskar, A. R., Gupta, V. K., Kumar, D., Singh, M. M. \& Sharma, N. (2010). Psychosocial disorders among children and some epidemiological correlates. Asian Pacific Disability and Rehabilitation Journal, 21(1), 80-89.

Lovibond, S.H. \&Lovibond, P.f. (1995). Manual for the Depression anxiety Stress Scales. (2nd Ed) Sydney: Psychology Foundation.

Marschark, M. (1993). Psychological development of deaf children. New York: Oxford University Press.

Mc Dermott, J. F., \& Akina, E. (1972). Understanding and improving the personality of children with physical handicaps. Clinical Pediatrics, 11, 130-134.

Narimani, M., \& Mousazadeh, T. (2010). Comparing self-esteem and self-concept of handicapped and normal students. Procedia- Social and Behavioural Sciences, 2(2), 1554-1557.

Nosek, M. A., Hughes, R.B., Swedlund, N., Taylor, H.B., \& Swank, P. (2003). Self esteem and women with disabilities. Social Science \& Medicine, 56, 737-47.

Omolayo, B. (2009). Self-Esteem and Self-Motivational Needs of Disabled and Non-Disabled: A Comparative Analysis. Journal of Alternative Perspectives in the Social Sciences, 1 (2), 449-458.

Puranen, N. N., Seuri, M., Simoli, A., \& Elo, J. (1999). Physically disabled at work: Need for ergonomic interventions, 9(4), 215- 225.

Reynell, R. (1970). A pine of disability. Scotland: Foreman \& Co.

Robson, J.M. (1988) Textual introduction: In M. Robson (ed.) Collected works of John Stuart Mill. Toronto University of Toronto Press.

Roessler, D.L. (1978) Learning theory and pro-social behaviour. Journal of Social Issue, 8, 151164.

(C) The International Journal of Indian Psychology, ISSN 2348-5396 (e) | ISSN: 2349-3429 (p) | 131 
Rosenberg, M. (1965). Society and the adolescent self-image. Princeton, NJ: Princeton University Press.

World Health Organization 2001. The International Classification of Functioning, Disability and Health (ICF). Geneva: WHO. http://www.who.int/classifications/icf/en/

How to cite this article: S Mushtaq, D Akhouri (2016), Self Esteem, Anxiety, Depression and Stress among Physically Disabled People, International Journal of Indian Psychology, Volume 3, Issue 4, No. 64, ISSN 2348-5396 (e), ISSN: 2349-3429 (p), DIP:18.01.128/20160304, ISBN: 978-1-365-32519-9 